\title{
Descrição estatística do ciclo diário do vento nos primeiros 100 metros de altura da C.L.P na localidade de Colonia Eulacio, Uruguai
}

\author{
Statistical description of diurnal cycle of wind profile in the first 100 meters of \\ height of the Planetary Boundary Layer, in Colonia Eulacio Uruguay.
}

\author{
Everton de Almeida Lucas, Alejandro Gutiérrez Arce, Marcelo Romero de Moraes, \\ Gabriel Cazes Boezio e José Cataldo Ottieri \\ evertoncerrito@gmail.com, aguti@fing.edu.uy, marceloromero@unipampa.edu.br, agcm@fing.edu.uy, jcataldo@fing.edu.uy
}

\begin{abstract}
Resumo
Neste trabalho é apresentada a análise do ciclo diário do perfil do vento em altura para os primeiros 100 metros da camada limite planetária, considerando medições na torre Colonia Eulacio (Uruguai). A torre analisada conta com medições de alta resolução vertical, possuindo anemômetros instalados entre $10.1 \mathrm{~m}$ e $101.8 \mathrm{~m}$, termômetros entre $3.4 \mathrm{~m}$ e $100.8 \mathrm{~m}$, medidas de direção do vento e radiação solar. É apresentada a velocidade média a distintas alturas, o que permite caracterizar a natureza do fluxo como a intensidade de turbulência, e o desvio padrão da direção do vento. Os estados de estabilidade atmosférica se descrevem a partir do gradiente de temperaturas em altura (dT/dZ). Durante os momentos posteriores ao amanhecer (inestabilidade atmosférica) se observa uma dimuição da velocidade média nas maiores alturas de medições (81.8 m e $101.8 \mathrm{~m}$ ) e um aumento da velocidade média nas menores alturas de medições $(10.1 \mathrm{~m}$ e $25.7 \mathrm{~m}$ ). A dispersão de dT/dZ é maior nos casos de estabilidade durante a noite, registrando-se valores superadiabáticos $\left(-0.02^{\circ} \mathrm{C} / \mathrm{m}\right)$ durante o dia. A intensidade de turbulência decresce com a altura para os diferentes estados de estabilidade associados ao ciclo diário, registrando-se aumento da mesma para condições de inestabilidade atmosférica.
\end{abstract}

Palavras-chave: camada limite planetária, campo de velocidades, estabilidade atmosférica, intensidade de turbulência, ciclo diário.

\begin{abstract}
In this work is presented a statistical description of wind profile in the first $100 \mathrm{~m}$ of height of the Planetary Boundary Layer, taking account the measurements in the tower Colonia Eulacio Uruguay. This tower has high vertical resolution of wind velocity measurements, form $10.1 \mathrm{~m}$ to $101.8 \mathrm{~m}$. Thermometer are installed in $3.4 \mathrm{~m}$ and $100.8 \mathrm{~m}$, also the tower is equipped with wind vane and pyranometer. We present the diurnal cycle of mean wind, intensity of turbulence in dependence of height, also standard deviation of direction is described as a measure of turbulence in wind. Stability state is computed with vertical gradient of temperature. Before sunrise (unstable condition) is seen a decrease in mean velocity of top levels (81.8 $\mathrm{m}$ and $101.8 \mathrm{~m})$ and increase in lower levels $(10.1 \mathrm{~m}$ and $25.7 \mathrm{~m}$ ). Higher dispersion in $\mathrm{dT} / \mathrm{dz}$ can be seen during night time (stable condition), superadiabatic values $-0.02{ }^{\circ} \mathrm{C} / \mathrm{m}$ can be seen during daytime with slow dispersion. Intensity of turbulence decrease with height, for all stability conditions, is seen a increase in intensity of turbulence for unstable condition.
\end{abstract}

Keywords: Planetary Boundary Layer, wind profile, stability conditions, intensity of turbulence, diurnal cycle. 


\section{Introdução}

Atualmente o Uruguai se encontra em uma etapa crescente de incorporação de energia eólica no sistema elétrico. Está previsto que a potência eólica instalada para o ano de 2016 representará aproximadamente $25 \%$ do total da potência instalada no país. Mediante um acordo entre a empresa elétrica nacional, a "Administración Nacional de Usinas y Transmisiones Eléctricas" (UTE) e a universidade pública do país, a "Universidad de la Republica" (UdelaR), há se desenvolvido em âmbito acadêmico uma ferramenta de previsões operacionais para os parques eólicos implantados no país. Esta ferramenta é repassada para a UTE, que faz uso da mesma para auxiliar no despacho de energia elétrica na rede de transmissão. Esta ferramenta de previsão para parques eólicos se encontra disponível em www.fing. edu .uy/cluster/eolica/.

No Brasil, também está se consolidando a expansão da energia eólica nos últimos anos, e uma das regiões que possui destaque no aproveitamento deste tipo de energia é o sul do estado do Rio Grande do Sul, conhecido como a região do pampa gaúcho. Nesta região se encontram complexos eólicos de grande porte, como o complexo eólico Cerro Chato, localizado no município de Santana do Livramento e o complexo eólico Campos Neutrais, localizado nos municípios de Santa Vitória do Palmar e Chuí, sendo este considerado o maior empreendimento da América Latina neste setor de energia, com a capacidade de produção de $583 \mathrm{MW}$ de energia elétrica. Nesta região, no ano de 2006, foi fundada pelo governo federal a Universidade Federal do Pampa (UNIPAMPA), com o intuito de que fossem realizados estudos e pesquisas em temas de interesse regional, com o intuito de contribuir para o desenvolvimento da metade sul do Rio Grande do Sul.

No ano de 2012 a Unipampa firma um convênio marco com a Universidad de la República (UdelaR), com o intuito de realizar estudos e projetos de pesquisa em conjunto, devido principalmente a proximidade geográfica entre as mesmas, destacando assim o seu caráter fronteiriço, pois muitos de seus campi encontram-se em cidades de fronteira com a Argentina e Uruguai. Com o forte tema da energia eólica tanto na região sul do Brasil como no Uruguai, impulsionado pela implantação de parques eólicos em ambas as regiões, é inaugurado ao final do mês de Fevereiro de 2015 o primeiro empreendimento eólico em conjunto entre os países (parque eólico Artilleros), localizado no departamento de Colonia, Uruguai, com capacidade instalada de 65.1 MW, e com investimentos provenientes da empresa elétrica pública uruguaia UTE, e da brasileira Eletrobras. Em Julho de 2015 é finalizada a obra de interconexão elétrica entre os dois países, onde os extremos da linha de transmissão encontram-se no município de Candiota/RS pelo lado brasileiro e San Carlos, localizado no departamento de Maldonado, em território uruguaio.

No âmbito educacional, em Agosto de 2015 é firmado o convênio de estágio entre a Unipampa e UdelaR, o que permite estudantes de ambas as universidades desenvolverem estágio curricular obrigatório em ambas as instituições. A partir do convênio estabelecido, surge um projeto entre o curso de Engenharia de Energia com sede na cidade de Bagé/RS e o Instituto de Mecânica dos Fluídos e Engenharia Ambiental (IMFIA), o qual está localizado na Faculdade de Engenharia (FING) da UdelaR, com sede em Montevideo. O tema central de estudo e pesquisa do projeto é a energia eólica.

O primeiro estudo realizado em conjunto é mostrado neste trabalho, onde são analisados dados de uma das torres anemométricas localizadas no Uruguai, denominada Colonia Eulacio, a qual forma parte da rede de anemômetros utilizados para a avaliação do recurso eólico por parte da empresa elétrica UTE. Tal estudo é o primeiro passo em busca do objetivo final proposto no projeto, que é desenvolver um sistema de previsão operacional de energia eólica para os parques do Rio Grande do Sul, nos mesmos moldes do sistema de previsão operacional desenvolvido pela UdelaR e utilizado pela empresa elétrica UTE.

\section{Rede de Medições no Uruguai}

O Uruguai possui como característica em seu relevo o fato de ter a prodominância de planícies em baixas altitudes. Conforme descrito por Cornalino (2015), com o intuito de prospectar a produção de energia eólica no Uruguai, no ano de 2007 foram realizadas as primeiras instalações de estações de medições pela UTE, onde se obteve a instalação de duas estações, sendo uma em dique Albuquerque (região central do Uruguai) e Sierra de los Caracoles (região sul do Uruguai). O principal objetivo seria definir qual a melhor localização para a instalação do primeiro parque eólico no país.

Em um segundo momento decidiu-se pela expansão da rede de medições, para que fosse realizada uma prospecção eólica que cobrisse todo o território. Para concretizar esta expansão foram utilizadas as torres de telefonia celular que se encontravam ao longo do território do país, sendo as mesmas de propriedade das empresas Antel e Movistar. As referidas torres de telefonia tem como característica possuírem alturas entre 70 e 100 metros. Levando em consideração que suas estruturas não são totalmente adequadas para que sejam realizadas medições de velocidade do vento, foram tomadas precauções especiais para que fossem realizadas medidas de qualidade. Atualmente estas medições compõem a melhor fonte histórica de dados de vento em altura disponíveis no país. 
No ano de 2010 se deu início a medições dedicadas, ou seja, foram instaladas torres com a finalidade específica de realizar medições para uso em energia eólica. Neste mesmo período também foram realizadas medições exploratórias em torres de telecomunicações, porém em quantidade bem menor quando comparada aos anos antecedentes a 2010.

As novas aplicações tecnológicas no tema de energia eólica, forneceram dados em alturas anteriormente pouco estudadas na camada limite planetária, localizadas entre 40 e 100 metros. Conforme descrito IEC 61400-1 (2005) os projetos de energia eólica precisam de medições de velocidade do vento à altura compatível com o eixo das turbinas eólicas. Com base nos dados necessários para os projetos eólicos, a empresa UTE instalou uma vasta rede de medições, compreendendo anemômetros, wind vanes, piranômetros e termômetros, os quais se encontram distribuídos por todo o país.

A figura 1 mostrada abaixo, ilustra a localização das torres de medições instaladas pela UTE ao longo do território uruguaio. Além disto é mostrada a altitude do terreno ao longo do país, com valores em metros detalhados na faixa de cores.
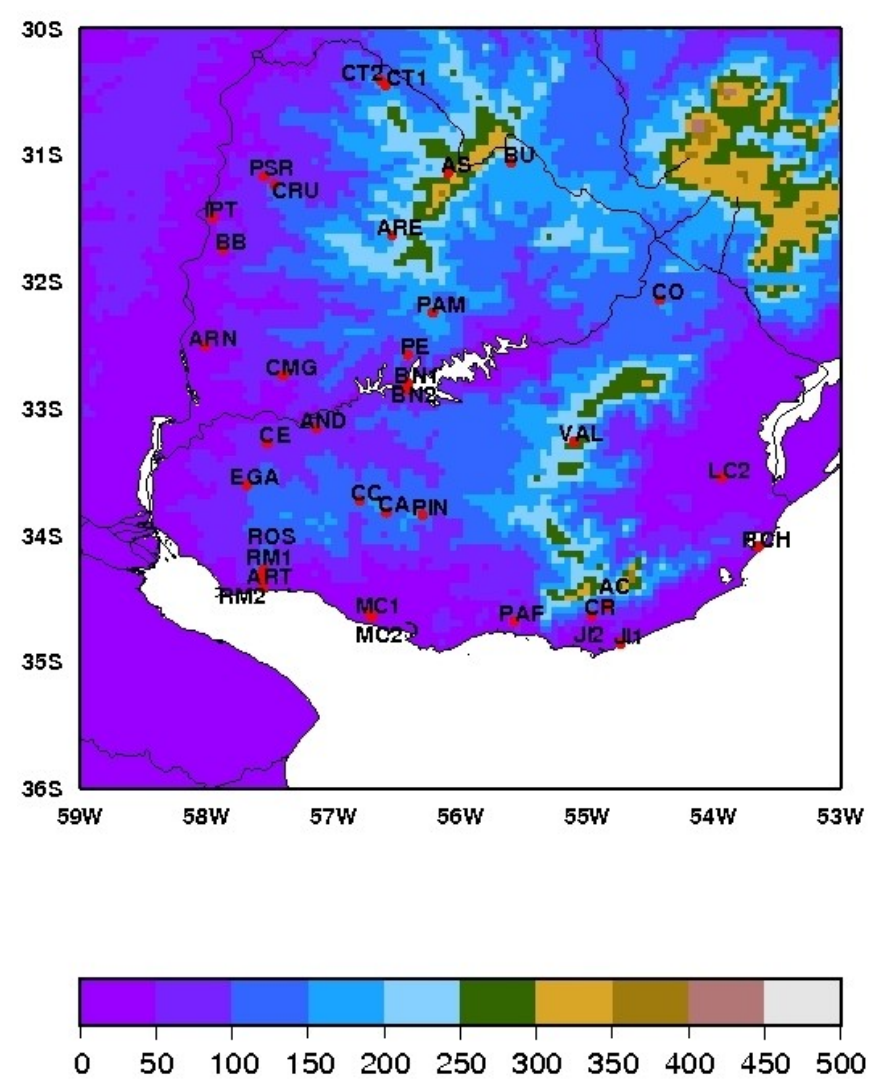

Figura 1: Distribuição das estações de medições de propriedade da UTE no território uruguaio, com suas respectivas altitudes do terreno.

A estação de medição onde está inserida a torre Co- lonia Eulacio, a qual é a fonte de dados para o presente trabalho, se encontra a sudoeste do país, indicada no mapa pela sigla "CE".

\subsection{Torre Colonia Eulacio}

A estação de medição utilizada para estudo é composta por uma torre de seção triangular, com 100.8 metros de altura, 0.45 metros de largura e está localizada conforme coordenadas UTM em 451405 E e 631752 S conforme sistema de coordenadas WGS-84. A elevação do terreno onde a mesma se encontra instalada é de aproximadamente $100 \mathrm{~m}$. A localidade onde se encontra a torre é denominada de Colonia Eulacio e está localizada no departamento de Soriano, na região sudoeste do Uruguai. A referida estação é de propriedade da "Administración Nacional de Usinas y Transmissiones Eléctricas" (UTE), à qual é uma empresa pública do Uruguai que se dedica as atividades de geração, distribuição e comercialização de energia elétrica, assim como prestação de serviços. Os equipamentos instalados na torre Colonia Eulacio possuem as seguintes características:

- Anemômetros: Marca NRG, modelo 40C do tipo "concha" (Anemômetro de Robinson).

- Wind Vanes: Marca NRG, modelo 200P.

- Termômetros: Marca NRG, modelo 110S.

- Piranômetro: Marca Li-cor, modelo LI200SZ.

A disposição vertical dos equipamentos de medições na torre, é detalhada na tabela 1, mostrada abaixo.

Tabela 1: Disposição vertical dos equipamentos de medições.

\begin{tabular}{ccc}
\hline Instrumento & Altura $(\mathrm{m})$ & Quantidade \\
\hline \hline Anemômetro I & 101.8 & 2 \\
Anemômetro II & 81.8 & 2 \\
Anemômetro III & 60.8 & 2 \\
Anemômetro IV & 25.7 & 1 \\
Anemômetro V & 10.1 & 1 \\
Wind Vane I & 100.8 & 1 \\
Wind Vane II & 60.8 & 1 \\
Termômetro I & 100.8 & 1 \\
Termômetro II & 3.4 & 1 \\
Piranômetro & 4.4 & 1
\end{tabular}

Analisando-se a tabela 1 percebe-se 5 (cinco) distintas alturas de medições realizadas por anemômetros, o que mostra a alta resolução vertical de medidas na torre Colonia Eulacio, dando ênfase ao seu detalhamento em medições de velocidade do vento. Conforme ilustrado na tabela 1 os anemômetros I, II e III que estão instalados nas 3 (três) maiores alturas de medições (101.8, 81.8 e 60. 
8 metros) estão dispostos em pares. Esta disposição dos equipamentos foi feita com o intuito de evitar erros nas medições destes instrumentos de medida, erros estes provenientes de efeitos causados pela estrutura da torre de medição no fluxo do vento. A figura 2 mostra a torre Colonia Eulacio e o entorno onde a mesma se encontra.

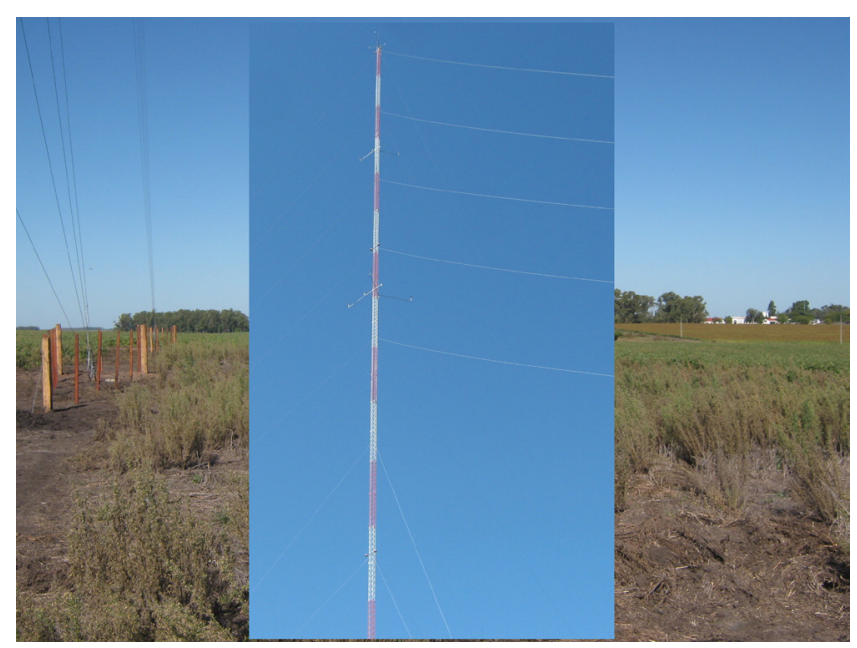

Figura 2: Foto da torre Colonia Eulacio e seu entorno.

A tabela 2, mostrada abaixo, informa a orientação em graus geográficos dos anemômetros utilizados na torre de medição, onde os anemômetros instalados por pares são identificados com as letras " $a$ " e " $b$ " de modo a distingui-los conforme os distintos ângulos de instalação.

Tabela 2: Orient. Geog. $\left(^{\circ}\right)$ dos anemômetros.

\begin{tabular}{ccc}
\hline Instrumento & Altura $(\mathrm{m})$ & Orient. Geog. $\left(^{\circ}\right)$ \\
\hline \hline Anemômetro I a & 101.8 & 350 \\
Anemômetro I b & 101.8 & 170 \\
Anemômetro II a & 81.8 & 19 \\
Anemômetro II b & 81.8 & 139 \\
Anemômetro III a & 60.8 & 20 \\
Anemômetro III b & 60.8 & 140 \\
Anemômetro IV & 25.7 & 24 \\
Anemômetro V & 10.1 & 24
\end{tabular}

Conforme demonstrado na tabela 2 a diferença em graus na orientação geográfica do par de anemômetros na altura de $101.8 \mathrm{~m}$ é de $180^{\circ}$ e para os localizados na altura de $81.8 \mathrm{~m}$ e $60.8 \mathrm{~m}$ a diferença é de $120^{\circ}$. A diferença em graus entre os anemômetros pares da altura de $101.8 \mathrm{~m}$ e os das alturas $81.8 \mathrm{~m}$ e $60.8 \mathrm{~m}$ é resultante do posicionamento dos mesmos na torre, pois os localizados em $101.8 \mathrm{~m}$ se encontram acima da estrutura metálica $(100.8 \mathrm{~m})$, portanto não tem suas medições interferidas pela estrutura da mesma. Para as 2(duas) alturas mais baixas (25.7 m e $10.1 \mathrm{~m})$ a orientação geográfica é de $24^{\circ}$.
Os dados obtidos pelo datalogger possuem medidas a cada 2 segundos, onde são armazenados os valores de leitura e feita uma média a cada 10 minutos, de onde são apresentados o desvio padrão, valores máximos e valores mínimos das variáveis medidas.

\subsubsection{Distorções Causadas pela Torre de Medição}

Conforme descrito por Cornalino (2015) a configuração da montagem e da torre sobre a que se encontram os instrumentos de medição influenciam sensivelmente na qualidade e confiabilidade dos dados obtidos pelos mesmos. A autora complementa, descrevendo que a qualidade das medições também é dependente de fatores como a solidez da torre, e o coeficiente de arrasto dos componentes que a compõem.

A norma IEC 61400-12-1 (2005), entitulada como "Power performance measurements of electricity producing wind turbines" trata em seu anexo G "Mounting of instruments on the meteorological mast" as condições a serem consideradas para a instalação de instrumentos de medições em uma torre, sejam estas de seção quadrada, triangular ou circular. Um dos principais fatores a serem considerados para que as leituras dos anemômetros não sejam afetadas, ou tenham o mínimo de distorção nas medições de velocidade do vento, está relacionada com a direção do fluxo incidente nos anemômetros assim como seus respectivos posicionamentos em relação a torre de medição.

Para a direção do fluxo incidente nos anemômetros se procura que o instrumento de medição não se encontre a jusante (downwind) da torre, ou seja, que o vento incidente no anemômetro não possua distorções causadas pela estrutura da torre. Este tipo de distorção é conhecido como efeito esteira.

Outro fator de suma importância é a distância dos instrumentos de medições em relação à estrutura da torre, pois além do efeito esteira, o fluxo do vento também pode ser afetado por uma perturbação importante causada pela desaceleração do mesmo em presença da estrutura da torre. Relacionado aos fatores já citados, ainda deve-se levar em consideração o tipo de seção transversal da torre de medição, que pode ser quadrada, circular ou triangular, sendo que para cada tipo há um distinto comportamento do fluxo, assim como são distintas as configurações de montagem.

Com base nestas informações, analisou-se as medidas dos anemômetros dispostos em 5(cinco) distintas alturas de medições na torre de Colonia Eulacio. Para os anemômetros instalados nas 3(três) maiores alturas de medições os dados provenientes da UTE já vinham com uma filtragem realizada conforme o indicado na IEC 61400-12-1 (2005), ou seja, durante determinada angulação de incidência do vento nos instrumentos, se um dos anemômetros estivesse localizado a jusante da torre 
a medição deste seria descartada e a medição do outro anemômetro instalado a mesma altura seria validada e consequentemente adicionada as medidas na série de medições. Sendo assim para os anemômetros dispostos em pares. A figura 3 abaixo, ilustra o fluxo no entorno de uma torre triangular reticulada com $\mathrm{Ct}$ de 0.5 . O Ct é o coeficiente de empuxo da estrutura em estudo, sendo dependente das dimensões da mesma, pois este está relacionado com o efeito esteira.

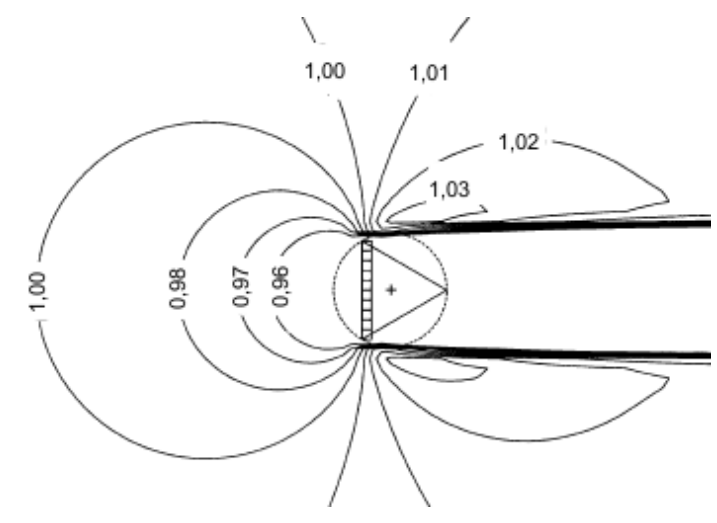

Figura 3: Gráfico de isovelocidades em torno de uma torre triangular reticulada (vento incidente da esquerda).

Para os anemômetros localizados nas 2(duas) menores alturas de medição $(25.7 \mathrm{~m}$ e $10.1 \mathrm{~m})$ foram analisados as direções e medidas realizadas pelos mesmos no período de 1(um) ano, assim como as suas distâncias em relação ao centro da torre de medição. Quanto a distância dos mesmos em relação ao centro da torre, os mesmos possuíam o valor de $2.25 \mathrm{~m}$. Considerando que a estrutura da torre é de seção triangular reticulada e com largura de $0.45 \mathrm{~m}$ considerou-se um $\mathrm{Ct}$ com valor de 0.95 , dados estes que conforme a norma mostram que o comprimento das hastes utilizadas para os anemômetros nestas 2(duas) referidas alturas foram corretamente dispostos. Quanto a direção do vento percebeu-se que os mesmos tinham suas medições efetadas em uma direção inferior a 3\% da série total medida (1 ano). Sendo assim suas medidas foram validadas pelo fato da direção afetada não ser significante para o período analisado, assim como as suas distâncias em relação ao centro da torre estarem de acordo com os valores mínimos exigidos na norma IEC 61400-12-1 (2005).

\section{Análise do Ciclo Diário}

Para a análise do ciclo diário se apresenta em uma primeira instância o registro de valores a cada $10(\mathrm{dez}) \mathrm{mi}-$ nutos. Logo se realiza uma análise estatística para valores horários que são calculados a partir de registros realizados pelo "datalogger" instalado na torre Colonia
Eulacio, o qual possui o mesmo intervalo de registro citado anteriormente. Os ciclos diários se representam calculando os valores médios das variáveis de interesse, assim como os percentis 16 e 84 para cada hora, considerando os dias de verão, outono, inverno e primavera para o período de 8 de Agosto de 2014 até 8 de Agosto de 2015.

\subsection{Interação entre a Radiação Solar, Tempe- ratura, Perfil de Velocidade do Vento e Intensidade de Turbulência na Camada Limite Atmosférica}

Nas figuras 4 e 5 são apresentados os valores registrados a cada dez minutos na torre de medição Colonia Eulacio para os dias 6 de Dezembro de 2014 e 15 de Julho de 2015 respectivamente. Estas figuras registram a velocidade do vento para as 5(cinco) distintas alturas de medições, as quais são atribuídas as seguintes cores: $101.8 \mathrm{~m}$ (azul), $81.8 \mathrm{~m}$ (vermelho), $60.8 \mathrm{~m}$ (verde), $25.7 \mathrm{~m}$ (preto) e 10.1 m (magenta).

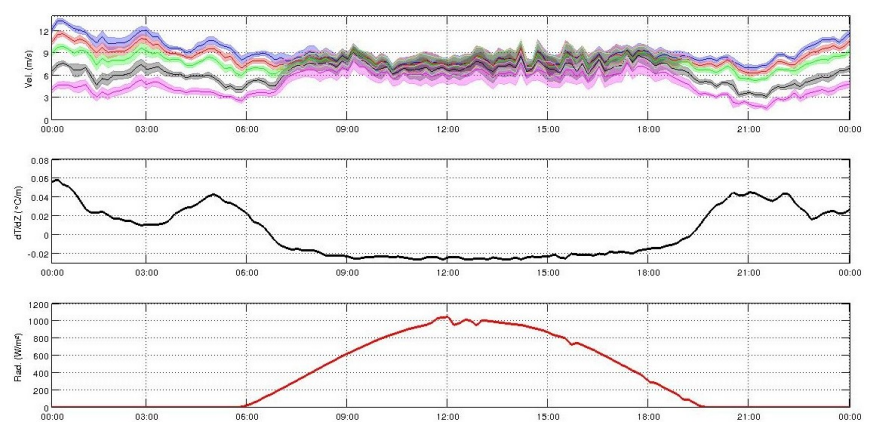

Figura 4: Comportamento dos perfis de vento, velocidade média, desvio padrão, gradiente de temperatura e radiação solar incidente no plano horizontal para o dia 6 de Dezembro de 2014 a partir de medições realizadas na torre Colonia Eulacio.
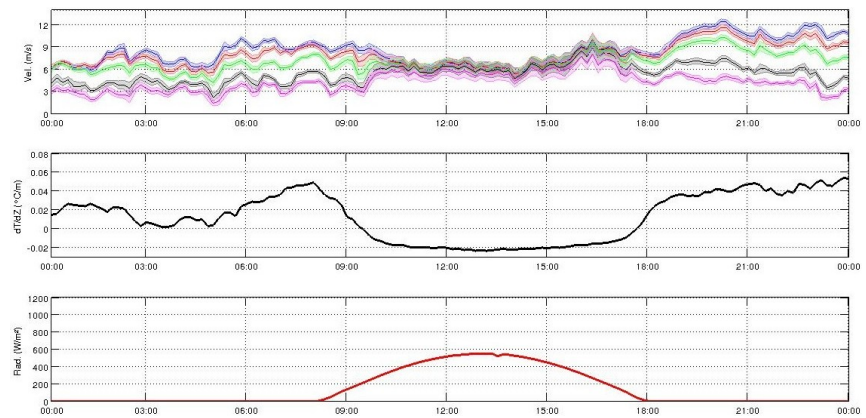

Figura 5: Comportamento dos perfis de vento, velocidade média, desvio padrão, gradiente de temperatura e radiação solar incidente no plano horizontal para o dia 15 de Julho de 2015 a partir de medições realizadas na torre Colonia Eulacio. 
Para o gráfico das velocidades do vento, a área sombreada representa o desvio padrão da mesma. Desta maneira se pode inferir a característica do fluxo com maior ou menor flutuação no entorno da velocidade média em função da largura da área sombreda, no primeiro quadro da figura. Também nas figuras 4 e 5 se apresentam os valores de gradiente de temperatura entre 100.8 $\mathrm{m}$ e $3.4 \mathrm{~m}(\mathrm{dT} / \mathrm{dZ})$, os quais podem ser visualizados no quadro central da figura. Os valores positivos de $\mathrm{dT} / \mathrm{dZ}$ indicam que a superficie terrestre possui uma temperatura menos elevada que a atmosfera, deste modo o calor sensível é transferido desde a atmosfera para superfície terrestre. Os valores negativos indicam que a atmosfera próxima está recebendo calor da superfície terrestre, sendo que esta recebe o fluxo de radiação solar que se registra no quadros localizados mais abaixo nas figuras 4 e 5 .

Nos dias selecionados se pode ver a vinculação entre o gradiente vertical de temperatura em altura que se produz pelo ciclo de radiação solar e a estrutura do fluxo, tanto em valores médios como na flutuação que se registra indicada pela área sombreada.

\subsection{Radiação Solar}

Na figura 6 se apresentam os valores de radiação solar incidentes no plano horizontal em termos de sua variação diária, registradas para as distintas estações do ano. A variação da radiação solar no Uruguai foi apresentada por Abal et.al (2011), que descreveu que os valores médios mensais da radiação solar incidentes no plano horizontal possuiam variação em média de $6.7 \mathrm{KWh} / \mathrm{m}^{2}$ em Janeiro a $2.1 \mathrm{KWh} / \mathrm{m}^{2}$ para o mês de Junho na região central do Uruguai. Integrando os valores de radiação incidente ao longo do dias analisados e verificando os registros descritos por Abal et.al (2011), a série de dados mostraou valores compatíveis com as descritas na bibliografia do autor.
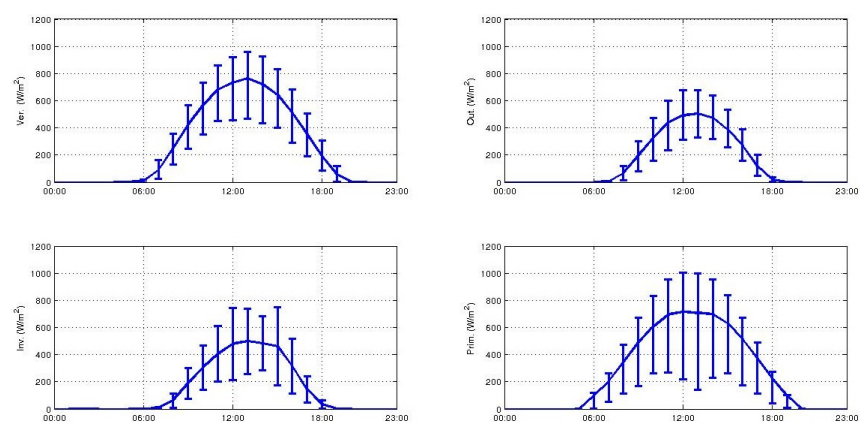

Figura 6: Variação anual da radiação solar incidente no plano horizontal na estação Colonia Eulacio, para a altura de 4.4 metros, As barras verticais mostram a média entre o $16^{\circ}$ e o $84^{\circ}$ percentis.

\subsection{Gradiente de Temperatura}

Na figura 7 se apresentam os valores de gradiente vertical de temperaturas ( $\mathrm{dT} / \mathrm{dZ}$ ) em termos de sua variação diária registrados para as distintas estações do ano. Arya (1998) apresenta a caracterização dos estados de estabilidade atmosférica a partir do gradiente de temperatura vertical.
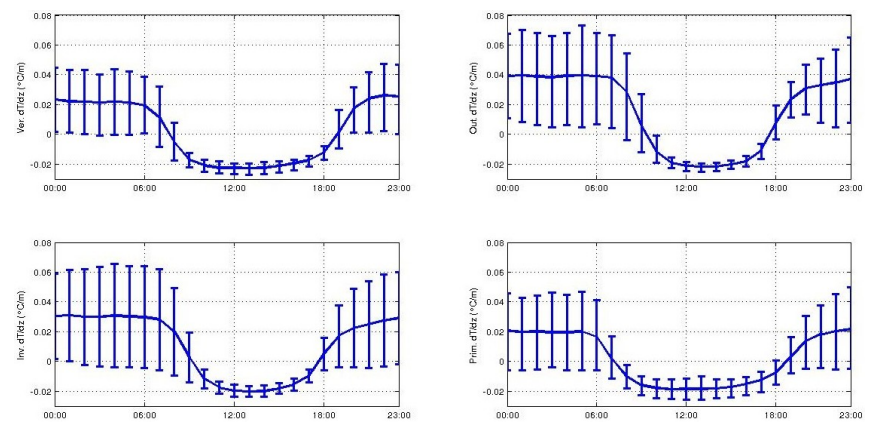

Figura 7: Variação anual do gradiente de temperatura registrado nas medições da torre Colonia Eulacio a alturas entre 3.4 e 100.8 metros, na unidade de ${ }^{\circ} \mathrm{C} / \mathrm{m}$. As barras verticais mostram a média entre o $16^{\circ}$ e o $84^{\circ}$ percentis.

A dispersão de dT/dZ é maior nos casos de estabilidade durante a noite, registrando-se valores superadiabáticos durante o dia. Os trabalhos de Czarnetzki (2012) e Takle (1983) documentam regimes superadiabáticos. Gutiérrez e Fovell (2015) descrevem o regime de estabilidade para 3(três) regiões do Uruguai onde destacam a singularidade da costa oceânica com uma menor estabilidade atmosférica no período noturno quando comparado aos registros analisados nas torres de medições continentais.

\subsection{Perfil de Velocidade do Vento}

Kaimal (1976) descreve a estrutura da camada limite instável, onde conclui que as camadas mais baixas tem uniformidade com o campo de velocidades, descreve também o processo de produção de turbulência de origem térmica. Em todo esse processo é determinante a magnitude de troca de calor com a superfície terrestre. Neste trabalho não se calcula nem se estima a troca de calor com a superfície, se infere a mesma de modo indireto a partir do gradiente de temperaturas em altura $\mathrm{dT} / \mathrm{dZ}$.

Wyngaard (1985) apresenta de modo conceitual as características da estabilidade e inestabilidade da camada limite planetária. Acevedo (2001) analisa a transição que se apresenta na condição de estabilidade na atmosfera ao entardecer. $\mathrm{O}$ autor analisa que a produção de turbulência pelos vórtices térmicos decai, devido ao resfriamento da superfície terrestre. Esta transição é mais abrupta nos casos de noites sem nebulosidade. A transi- 
ção se vê atenuada no caso de que se tenha a presença nebulosidade.

Na figura 8 se apresentam os valores médios de velocidades para as 5(cinco) distintas alturas de medição da torre Colonia Eulacio, onde as mesmas são representadas pelas seguintes cores: $101.8 \mathrm{~m}$ (azul), $81.8 \mathrm{~m}$ (vermelho), $60.8 \mathrm{~m}$ (verde), $25.7 \mathrm{~m}$ (preto) e $10.1 \mathrm{~m}$ (magenta).
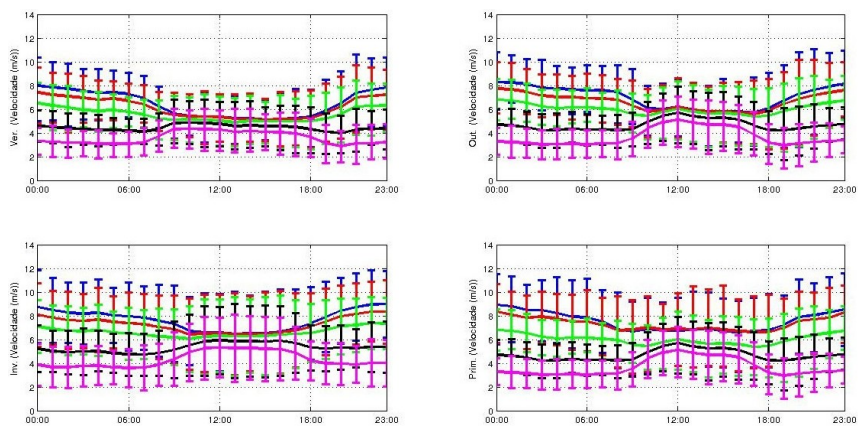

Figura 8: Variação anual do perfil de velocidade do vento na estação de medição Colonia Eulacio a 5(cinco) distintas alturas, situadas entre 10.1 e 101.8 metros, na unidade de $\mathrm{m} / \mathrm{s}$. As barras verticais mostram a média entre o $16^{\circ}$ e o $84^{\circ}$ percentis.

De acordo com a figura 8 durante os períodos posteriores ao amanhecer (inestabilidade atmosférica) se observa uma baixa na velocidade média nas camadas mais altas medidas ( $81.8 \mathrm{~m}$ e $101.8 \mathrm{~m}$ ), assim como um aumento nas velocidades mais baixas (10.1 m e $25.7 \mathrm{~m}$ ).

\subsection{Intensidade de Turbulência}

A intensidade de turbulência (IT) é definida conforme a equação (1), caracterizada como sendo desvio padrão dividido pela média da velocidade. A IT é um fator relevante para a descrição da força do vento e as classes de turbinas eólicas a serem selecionadas, conforme descrito na norma IEC 61400-1 (2005), em referência ao parâmetro que descreve a natureza do recurso de energia do vento em locais analisados. A IT também é um parâmetro relevante para a estimativa da produção de energia eólica, já que a mesma descreve o regime que está presente na conversão da energia cinética por turbina de vento. A IT descreve a variação média da velocidade medida na torre e pode mostrar uma medida da turbulência em uma capacidade de descrição estatística, mais relacionada com grandes escalas de turbulência.

$$
I T=\frac{\sigma}{\bar{V}}
$$

Na figura 9 se apresentam os valores médios de intensidade de turbulencia, distinguidos pelas seguintes cores: $101.8 \mathrm{~m}$ (azul), $81.8 \mathrm{~m}$ (vermelho), $60.8 \mathrm{~m}$ (verde), $25.7 \mathrm{~m}$ (preto) e $10.1 \mathrm{~m}$ (magenta).
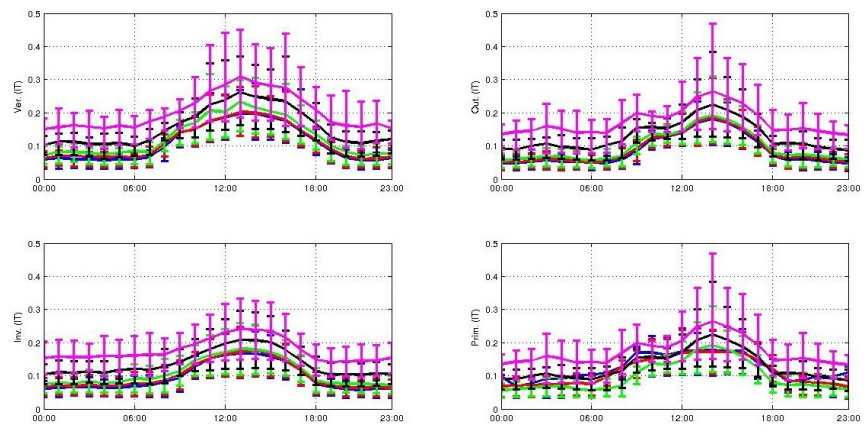

Figura 9: Variação anual da intensidade de turbulência na estação de medição Colonia Eulacio a 5(cinco) distintas alturas, situadas entre 10.1 e 101.8 metros. As barras verticais mostram a média entre o $16^{\circ}$ e o $84^{\circ}$ percentis.

A figura 9 mostra o decréscimo da intensidade de turbulência com a altura para os distintos estados de estabilidade. O decréscimo se percebe até 60 metros logo se apresentam valores similares de intensidade de turbulência entre $60 \mathrm{~m}$ e $101.8 \mathrm{~m}$. As maiores alturas se corresponden com a área de varredura das pás do aerogeradores de eixo horizontal instalados em parques eólicos. Gutiérrez,A. (2015) apresenta a descrição dos cortantes de velocidade na área de varredura das pás dos aerogeradores de eixo horizontal, assim como propõe uma metodologia para a simulação de intensidade de turbulência a partir do quociente entre velocidade de friç̧ão e a velocidade média a partir de simulações realizadas com o modelo WRF-ARW com a parametrização da camada limite planetária (Mellor e Yamada (1982)).

\subsection{Direção do Vento}

A figura 10 apresenta o desvio padrão da direção do vento, sendo este um indicador também da turbulência no campo de velocidades.
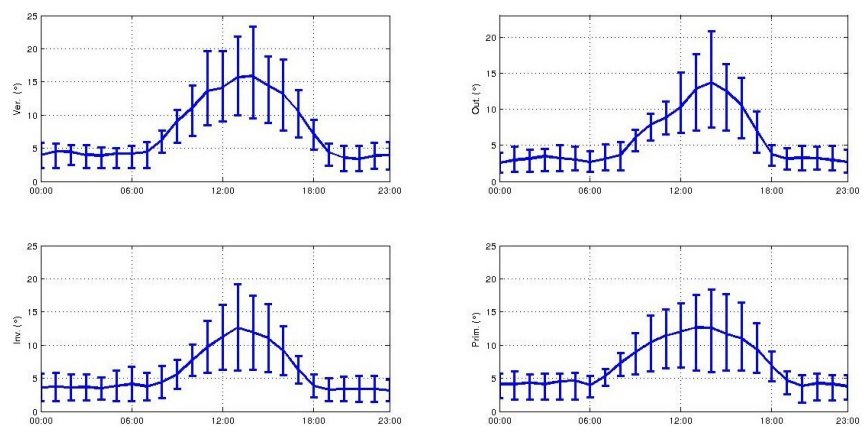

Figura 10: Variação anual do desvio padrão na direção do vento, na altura de 60.8 metros, na unidade de graus. As barras verticais mostram a média entre o $16^{\circ}$ e o $84^{\circ}$ percentis.

O desvio padrão da direção do vento mostra um 
comportamento similar ao da intensidade de turbulência, notando-se um incremento para condições de inestabilidade, o qual é um indicador da presença de vórtices térmicos. Os aerogeradores de eixo horizontal se orientam automaticamente a direção predominante do vento, em busca de maximar a captção do fluxo de energia cinética que atravessa a área varrida pelas pás. A medida de direção do vento não é representativa da área total de varredura das pás do aerogerador, de toda a forma se poderia inferir que não é possível orientar em todos os instantes o aerogerador no sentido normal ao fluxo do vento, já que o sistema de orientação está relacionado com a medida analisada da direção do vento localizado na nacele do aerogerador. Em casos de condições de atmosfera estável (baixa turbulência) se pode visualizar na figura 8 que o gradiente de velocidade em altura é maior que no caso de inestabilidade, onde se tem um perfil de velocidades médias aproximadamente uniformes na área de varredura das pás do aerogerador.

As figuras 8, 9 e 10 descrevem a natureza do fluxo que pode ser captado pela área de varredura das pás dos aerogeradores, onde o ciclo diário é determinante em termos da natureza do campo de velocidades, que se desenvolve na camada limite. Aos efeitos de considerar o desenvolvimento de modelos de previsões para geração de origem eólica, se deve considerar a natureza destes processos para um melhor ajuste dos modelos de pós-processamento estatístico de variáveis que possam ser geradas por modelos de circulação regional.

\section{Conclusões}

Neste trabalho a transição de estabilidade atmosférica logo ao entardecer pode ser visualizada tanto no ciclo diário da intensidade de tubulência como no desvio padrão da direção dos indicadores da mudança na natureza do fluxo. Durante os momentos posteriores ao nascer do sol (inestabilidade atmosférica) se observa uma dimuição na velocidade média nas camadas mais altas medidas ( $81.8 \mathrm{~m}$ e $101.8 \mathrm{~m}$ ) e um aumento na velocidade nas camadas mais baixas (10.1 m e $25.7 \mathrm{~m})$. A dispersão de $\mathrm{dT} / \mathrm{dZ}$ é maior nos casos de estabilidade durante a noite, registrando-se valores superadiabáticos $\left(-0.02{ }^{\circ} \mathrm{C} / \mathrm{m}\right)$ durante o dia. A intensidade de turbulência decresce com a altura para os diferentes estados de estabilidade associados ao ciclo diário, registrando-se um aumento da mesma para condições de inestabilidade. Aos efeitos de melhorar a ferramenta de previsão para energia eólica, se deve aprofundar a análise de modo que venha prever os parâmetros que caracterizem a natureza do fluxo, como a intensidade de turbulência e velocidade média do vento.

\section{Agradecimentos}

Agradecemos a Administración Nacional de Usinas y Trasmisiones Eléctricas (UTE) por fornecer os dados que serviram de base ao estudo realizado.

\section{Referências}

Abal,G., D' Angelo,M., Cataldo,J., Gutiérrez,A. (2011). Mapa Solar del Uruguay Versión 1.0 Memoria Técnica. ISBN 978-9974-0- 0847-2.

Acevedo,O.C, Fitzjarrald, D.R.(2001) The Early Evening Surface-Layer Transition: Temporal and Spatial Variability. Journal of the Atmospheric Sciences: Vol. 58, No. 17, pp. 2650-2667.

Arya,S.Pal (1998). Air Pollution Meteorology and Dispersion (1st Edition ed.). Oxford University Press. ISBN 0-19-507398-3.

Cornalino,E. (2015). Descripción del Comportamiento del Recurso Eólico Nacional para su Modelado dentro del Sistema Eléctrico, Universidad de la Republica, UdelaR, Uruguay.

Czarnetzki, A. C. (2012). Persistent daytime superadiabatic surface layers observed by a microwave temperature profiler. Preprints, 37th Natl. Wea. Assoc. Annual Meeting, Madison, WI, Natl. Wea. Assoc., P2.55.

Gutiérrez,A. , Fovell, R.G. (2015). Gust forecasting in Uruguay in support of wind energy. 14th International Conference on Wind Engineering - Porto Alegre, Brazil.

Gutiérrez, A. (2015), Description of Intensity of Turbulence IT in dependence with stability regime at swept area of wind turbines blades heights. 14Th International Conference on Wind Engineering - Porto Alegre, Brazil.

IEC 61400-1 (2005). Third edition. Wind turbines - Part 1: Design requirements .

IEC 61400-12-1 (2015). First edition. Wind turbines - Part 12-1: Power performance measurements of electricity producing wind turbines

Kaimal, J. C., Wyngaard,J. C. „Haugen,D.A, Coté,.R, Izumi,Y., Caughey,S.J., Readings,C.J. (1976): Turbulence Structure in the Convective Boundary Layer.

Mellor,G.L, Yamada,T. (1982). Development of a turbulence closure model for geophysical fluid problems. Rev. Geophys. Space Phys., 20, 851-875. 
Takle, E. S. (1983). Climatology of superadiabatic conditions for a rural area. J. Climate Appl. Meteor., 22, $1129-1132$.

Wyngaard, J.C.(1985). Structure of the Planetary Boundary Layer and Implications for its Modeling. J. Climate Appl. Meteor., 24, 1131-1142. 